\title{
Perilaku Minat Wisatawan Terhadap Ekowisata Hutan Mangrove Baros Bantul
}

\author{
I Putu Hardani HD \\ STP AMPTA YOGYAKARTA \\ E-mail :Iputu.hardani@gmail.com
}

\begin{abstract}
The purpose of this study was to determine the behavioral interest of tourists who visited the Baros Bantul Mangrove Forest Ecotourism destination. To this end, field surveys have been carried out on the Baros Bantul Mangrove Ecotourism Center as a center for ecotourism for Mangrove Forests in Bantul. The survey was received from 100 participants consisting of tourists visiting the Baros Bantul Mangrove Forest Ecotourism. After the analysis, an assessment of the interest of tourists in the area was carried out. Research findings The need to develop a program of development activities that combines the potential of nature and culture to attract more tourist visits Introducing and promoting the tourism potential of Baros Mangrove, Development of facilities and infrastructure, Increasing the capacity of human resources in the local community in managerial training and technical training on welcoming tourists and Improving access to the Mangrove Tourism Baros Bantul
\end{abstract}

\section{Keywords: Ecotourism Tourist Visits, Interests, Visitors, Baros Bantul Mangrove Ecotourism}

\begin{abstract}
Abstrak - Tujuan penelitian ini adalah untuk mengetahui perilaku minat wisatawan yang mengunjungi tujuan Ekowisata Hutan Mangrove Baros Bantul. Untuk tujuan ini, survei lapangan telah dilakukan di Ekowisata Hutan Mangrove Baros Bantul sebagai pusat ekowisata Hutan Mangrove di Bantul . Survei diterima dari 100 peserta yang terdiri atas wisatawan yang berkunjung ke Ekowisata Hutan Mangrove Baros Bantul. Setelah analisis, dilakukan penilaian tentang minat wisatawan di daerah tersebut. Temuan penelitian Perlunya mengembangkan program kegiatan pengembangan yang menggabungkan potensi alam dan budaya untuk ;lebih menarik minat kunjungan wisatawan. Mengenalkan dan mempromosikan potensi wisata Mangrove Baros, Pengembangan sarana dan prasarana, Peningkatan kemampuan SDM masyarakat lokal dalam pelatihan manajerial dan pelatihan teknis penyambutan wisatawan serta Pebaikan akses menuju ke Wisata Mangrove Baros Bantul
\end{abstract}

Kata kunci: Perilaku Kunjungan Wisatawan Ekowisata, Minat, Pengunjung, Ekowisata Hutan Mangrove Baros Bantul

\subsection{Latar Belakang}

Sektor pariwisata tumbuh dengan pesat seiring dengan tuntutan gaya hidup dan kebutuhan akan rekreasi. Pariwisata menjadi bagian yang penting dalam kehidupan manusia sebagai salah satu kebutuhan hidup sekaligus sebagai gaya hidup. Dengan adanya perkembangan ini, maka pemerintah berlomba memajukan potensi pariwisata yang ada melaluli beberapa program dan kebijakan yang berpihak pada pemberdayaan dan optimalisasi potensi sumber daya alam dan sumber daya manusia, dimana sektor pariwisata ini berperan terhadap kesejahteraan masyarakat disekitar obyek dan daya tarik wisata. Optimalisasi dan pemberdayaan baik sumber daya alam maupun sumber daya manusia ini mampu menggerakan geliat perokonomian dan pendapatan asli daerah. Hal ini sebagai salah satu efek perkembangan dari pariwisata, jika suatu daerah berkembang pada sektor pariwisatanya maka akan menimbulkan minat dari para wisatawan untuk melakukan perjalanan dengan mengunjungi obyek dan daya tarik wisata tersebut. Rasa ingin tahu dan motivasi untuk eksistensi mendorong masyarakat melakukan perjalanan wisata dengan mengunjungi potensi wisata tersebut.

Salah satu pengembangan wisata yang mampu menarik minat wisatawan untuk berkunjung adalah wisata berbasis Ekologi seperti wisata alam. Ekowisata seperti halnya pariwisata mempunyai dua arti penting yaitu sebagai perilaku (behavior) dan sebagai industri, sebagai perilaku merupakan sikap pelaku pariwisata, bagaimana yang seharusnya dilakukan dalam pengembangan pariwisata di kawasan hutan. Sebagai industri pelaku pariwisata baik pemerintah, swasta, maupun masyarakat, harus bersama-sama mengembangkan suatu mekanisme dalam pengembangan ekowisata, sehingga dapat memberikan manfaat secara ekonomi, fisik, sosial dan budaya serta mampu memberikan manfaat bagi masyarakat setempat. Oleh karena itu, pengertian ekowisata dengan dilatar belakangi oleh kesadaran akan tanggung jawab atas kawasan yang dikunjungi dalam melakukan kegiatan di alam, dalam hal ini terkandung suatu sikap untuk merubah perilaku dari apa yang selama ini dilakukan 
menjadi apa yang seharusnya dilakukan, sedangkan pengertian ekowisata sebagai suatu industri mengembangkan pemahaman bahwa kegiatan-kegiatan wisata di wilayah yang masih alami harus dilakukan dengan membangun kerjasama seluruh pelakunya: Pemerintah, swasta, dan masyarakat, serta manfaat yang diperoleh kembali selayaknya tidak hanya kepada para pelakunya namun kepada usaha-usaha untuk melestarikan wilayah tersebut dan mensejahterakan masyarakatnya..

Salah satu kabupaten di Daerah Istimewa Yogyakarta adalah Kabupaten Bantul, mampu mengembangkan potensi ekowisata berupa Hutan Mangrove dan Hutan Becici. Kedua obyek wisata ini mampu memberikan kontribusi tersendiri dalam hal kunjungan wisatawan baik wisatawan nusantara maupun wisatawan mancanegara.

Dengan pengelolaan lingkungan yang baik, kawasan ekowisata dapat memberikan kontribusi penting bagi kesejahtraan masyarakat, sebaliknya jika dikelola dengan buruk, akan meninggalkan kerusakan. Oleh Karena itu informasi dasar tentang perilaku kunjungan ekowisata; kepekaan terhadap lingkungan; niat mengunjungi ekowisata dan persepsi pengunjung ekowisata dapat menjadi basis penataan ekonomi ekowisata, nilai konservasi, biaya kerusakan lingkungan. dan mengaudit dampak kegiatan ekowisata.

\subsection{Kajian Pustaka}

Gambar 1.1 memvisualisasikan bahwa kepedulian lingkungan (KL) secara teoritis memiliki pengaruh terhadap niat mengunjungi ekowisata (NME), persepsi wisatawan ekowisata (PWE) dan perilaku kunjungan ekowisata (PKE), efek KL ke PKE dimediasi oleh NME dan PWE.

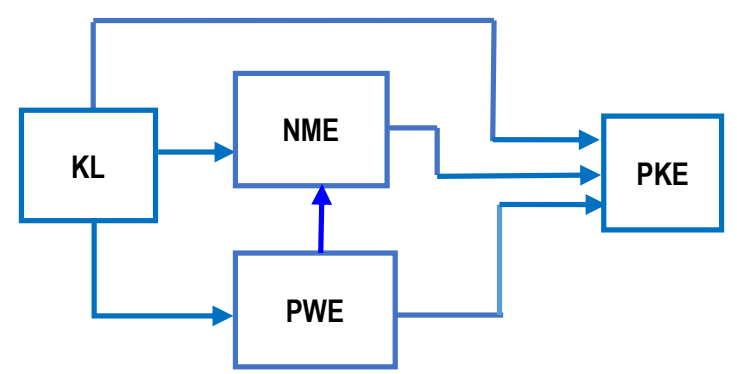

Gambar 1. 1. Perilaku Kunjungan Ekowisata

\subsubsection{Konsep Dasar Ekowisata}

Ekowisata merupakan perwujudan konsep konsumsi produk alam (hijau) yang telah mendapat pengakuan secara internasional, meningkatkan pengelolaan pariwisata, mendukung pengembangan pariwisata berkelanjutan. Konsumsi produk alam (hijau) menjadi kekuatan penting dalam melindungi lingkungan. Menurut Budeanu (2007) jika wisatawan memilih tinggal dengan fasilitas yang disesuaikan dengan lingkungan, dampak negatip selama masa tinggal mereka secara otomatis akan turun.

Ecotourist melakukan perjalanan ke kawasan wisata alam ini untuk menikmati lingkungan alam dengan dampak minimal. Ekowisata tumbuh sebagai konsekuensi ketidakpuasan terhadap bentuk pariwisata konvensional, yang telah mengabaikan ekologi dan berotientasi pada keuntungan semata. Beberapa variabel kunci dan prinsip ekowisata, yang memisahkan pariwisata alam dari pariwisata konvensional : seperti edukasi nilai, menghargai lingkungan alam, kebutuhan dan motivasi untuk melindungi dan konservasi lingkungan

Mempromosikan kepuasan pengunjung merupakan tugas penting provider layanan pariwisata dan cara untuk memerangi perilaku yang merusak lingkungan. Agar ekowisata itu berhasil dan pengelolaan kawasan lindung yang lestari, dampak pengunjung harus diidentifikasi dan dihindari atau diminimalisir, pemeliharaan fasilitas pengunjung yang sesuai dan edukasi pengunjung (Farrell and Marion, 2001).

Pengembangan ekowisata di dalam kawasan wisata dapat menjamin keutuhan dan kelestarian ekosistem destinasi tersebut. Ecotraveler menghendaki persyaratan kualitas dan keutuhan ekosistem. Oleh karenanya terdapat beberapa butir prinsip pengembangan ekowisata yang harus dipenuhi. Apabila seluruh prinsip ini dilaksanakan maka ekowisata menjamin pembangunan yang ecological friendly dari pembangunan berbasis kerakyatan (commnnity based). The Ecotourism Society (Eplerwood, 1999) menyebutkan ada delapan prinsip, yaitu:

1. Mencegah dan menanggulangi dampak dari aktivitas wisatawan terhadap alam dan budaya, pencegahan dan penanggulangan disesuaikan dengan sifat dan karakter alam dan budaya setempat.

2. Pendidikan konservasi lingkungan. Mendidik wisatawan dan masyarakat setempat akan pentingnya arti konservasi. Proses pendidikan ini dapat dilakukan langsung di alam.

3. Pendapatan langsung untuk kawasan. Mengatur agar kawasan yang digunakan untuk ekowisata dan manajemen pengelola kawasan pelestarian dapat menerima langsung penghasilan atau pendapatan. Retribusi dan conservation tax dapat dipergunakan secara langsung 
untuk membina, melestarikan dan meningkatkan kualitas kawasan pelestarian alam.

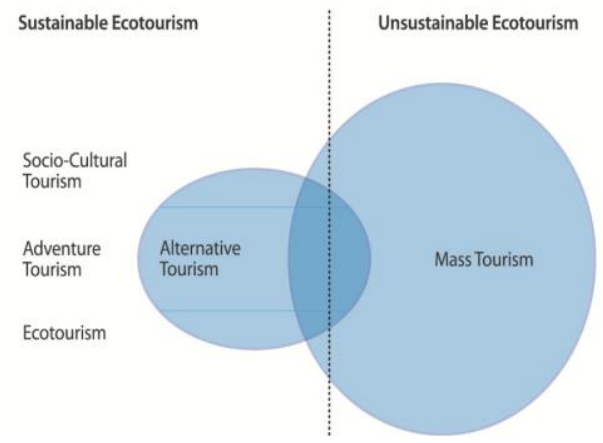

Gambar 2.1. Diferensiasi Sustainable - Unsustainable

$$
\text { Ecotourism }
$$

4. Partisipasi masyarakat dalam perencanaan. Masyarakat diajak dalam merencanakan pengembangan ekowisata. Demikian pula di dalam pengawasan, peran masyarakat diharapkan ikut secara aktif.

5. Penghasilan masyarakat. Keuntungan secara nyata terhadap ekonomi masyarakat dari kegiatan ekowisata mendorong masyarakat menjaga kelestarian kawasan alam.

6. Menjaga keharmonisan dengan alam. Semua upaya pengembangan termasuk pengembangan fasilitas dan utilitas harus tetap menjaga keharmonisan dengan alam.

7. Daya dukung lingkungan. Pada umumnya lingkungan alam mempunyai daya dukung yang lebih rendah dengan daya dukung kawasan buatan. Meskipun mungkin permintaan sangat banyak, tetapi daya dukunglah yang membatasi.

\subsubsection{Ekowisata Berkelanjutan}

Ekowisata yang berkembang akan memberikan dampak positif bagi keberlanjutan suatu obyek daya tarik wisata itu sendiri. Sementara ekowisata berkelanjutan memiliki variasi, sebagian besar definisi ekowisata kedalam bentuk yang dikhususkan dengan penyesuaian tiga kriteria:

1. Menyediakan konservasi lingkungan;

2. partisipasi masyarakat;

3. menguntungkan dan mandiri

Seperti yang ditunjukkan pada gambar 2.2, menunjukkan diferensiasi antara keberkelanjutan ekowisata dengan pariwisata yang tidak berke-lanjutan, tidak ada batas mutlak antara pariwisata berkelanjutan dan tidak berkelanjutan (Eriksson, 2003). Menurut Weaver (2001) bahwa ekowisata ada dalam klasifikasi jenis pariwisata yang lebih luas, yang pada tingkat awal, yang dapat dibagi menjadi 'pariwisata massal' dan 'wisata alternatif'. 'Wisata massal terlihat sebagai bentuk pengembangan pariwisata yang lebih tradisional dimana short-term dan freemarket.

Prinsip mendominasi dan memaksimalkan pengembangan pariwisata dilakukan berdasarkan perbedaan karakter wisata massal maupun karakter ekowisata seperti dalam tabel 2.1 berikut ini.

Table $2.1 \quad$ Distinct characteristics between mass tourism and ecotourism

\begin{tabular}{|c|c|}
\hline Masstourism. & Ecotourism \\
\hline Large groups of visitors & Small groups of visitors \\
\hline Urban & Rural \\
\hline $\begin{array}{l}\text { Touristic general marketing } \\
\text { activities }\end{array}$ & Eco-marketing activities. \\
\hline $\begin{array}{l}\text { Average prices for } \\
\text { purposes of market } \\
\text { penetration }\end{array}$ & $\begin{array}{l}\text { High price with purpose } \\
\text { of filtering the market }\end{array}$ \\
\hline Impact on natural environment & $\begin{array}{l}\text { Little impact on the } \\
\text { natural environment }\end{array}$ \\
\hline Advanced control options & $\begin{array}{l}\text { Limited possibilities of } \\
\text { control }\end{array}$ \\
\hline $\begin{array}{l}\text { Management based on } \\
\text { macroeconomic } \\
\text { principles }\end{array}$ & $\begin{array}{l}\text { Management based on } \\
\text { local } \\
\text { principles }\end{array}$ \\
\hline $\begin{array}{l}\text { Anonymous relationship } \\
\text { between visitors and } \\
\text { local community }\end{array}$ & $\begin{array}{l}\text { Personalized } \\
\text { relationships between } \\
\text { visitors } \\
\text { and local community }\end{array}$ \\
\hline General development goals & $\begin{array}{ll}\text { Local } & \text { development } \\
\text { objectives }\end{array}$ \\
\hline $\begin{array}{l}\text { Behavior-oriented } \\
\text { leisure } \\
\text { activities/entertainment } \\
\text { opponents to } \\
\text { education and training } \\
\text { actions }\end{array}$ & $\begin{array}{l}\text { Loyalty in the process of } \\
\text { training and education } \\
\text { for appropriate conduct } \\
\text { for the natural } \\
\text { environment }\end{array}$ \\
\hline $\begin{array}{l}\text { Intensive development of } \\
\text { tourism facilities }\end{array}$ & $\begin{array}{l}\text { Reduced development } \\
\text { of tourism facilities }\end{array}$ \\
\hline
\end{tabular}

Ekowisata merupakan komponen pendukung wisata berkelanjutan, dimana wisata berkelanjutan fokus dalam tiga bidang kajian, sebagai berikut :

1. Kualitas - pengalaman berharga bagi wisatawan yang mengunjungi obyek ekowisata dan peningkatan kualitas hidup masyarakat sekitar ekowisata melalui identitas budaya, pengentasan kemiskinan, dan kualitas lingkungan

2. Kontinuitas - Eksploitasi dilakukan pada tingkat optimal yang memungkinkan pelestarian dan Regenerasi sumber daya alam;

3. Keseimbangan antara kebutuhan industri pariwisata, perlindungan lingkungan, dan masyarakat lokal melalui pemerataan manfaat di antara para pemangku kepentingan

\subsubsection{Perilaku Kunjungan Ekowisata}


Jenis dan kualitas pengetahuan yang dimiliki pengunjung, mengintroduksi apa yang seharusnya diketahui oleh pengunjung, membangun kesadaran ekowisata dan memahami pentingnya keberlanjutan ekowisata (Sharma \& Sharma, 2013). Pentingnya konsep ekowisata berasal dari tuntutan dan tekanan pelanggan, investor, pemerintah dan LSM yang kemudian mendorong banyak provider pariwisata mengembangkan inisiatif berkelanjutan usaha mereka dengan strategi, program, operasi dan mitra pasokan perusahaan yang memiliki komitmen untuk meningkatkan kelestarian lingkungan (Chen et al, 2006).

Informasi dan promosi yang benar dapat mempropokasi niat kunjungan ekowisata untuk mendorong perilaku kunjungan ekowisata (PKE). PKE didefinisikan sebagai tindakan sadar yang dilakukan seseorang untuk meminimalkan dampak negatif dari aktivitas wisatawan terhadap ekowisata atau untuk memperbaiki ekowisata. Wisatawan yang memiliki kesadaran tinggi terhadap ekowisata, mereka akan mengunjungi dan bersedia membayar lebih untuk tujuan ekowisata (Sharma \& Sharma, 2013). Kesadaran ekowisata didefinisikan sebagai $P K E$ yang bersumber dari indikator psikologis seperti kepercayaan, nilai, sikap, dan pengetahuan (Lafuente, 2010) yang mendorong keterlibatannya dalam PKE.

\subsubsection{Niat Mengunjungi Ekowisata}

Aman, Harun, and Hussein, (2012) mendefinisikan niat sebagai kekuatan komparatif konsumen untuk bertindak berdasarkan perilaku tertentu. Dalam ekowisata, Niat mengunjungi ekowisata (NME) disebut sebagai kesempatan dan kemauan wisatawan yang memprioritaskan untuk kunjungan pada produk hijau dibanding produk tradisional. NME didefinisikan sebagai seberapa kuat keinginan untuk melakukan perjalanan ke destinasi hijau di wilayah tertentu. NME adalah diterminasi perilaku aktual wisatawan, artinya karena niat untuk mengunjungi produk hijau meningkat, maka kemungkinan besar wisatawan akan melakukan kunjungan itu. NME tidak dapat digeneralisasi secara universal karena karakteristik perilaku dan budaya masyarakat berbeda demikian juga permintaan terhadap produk ekowisata juga tidak akan seragam (Rahbar dan Wahid, 2011).

Wisatawan yang khawatir apakah destinasi yang mereka kunjungi benar-benar ekowisata atau tidak, keraguan mereka tidak memberi peluang tambahan rupiah untuk produk yang bukan ekowisata dan mereka tidak pernah mau berkompromi dengan kualitas ekowisata. Produk ekowisata dapat menjadi power penarik dan pendorong kunjungan, jika produk ekowisata itu dapat memenuhi kebutuhan dan keinginan wisatawan serta fitur lingkungan menambah nilai jual produk.

NME menunjukkan kepedulian terhadap lingkungan. NME adalah faktor penting untuk menentukan perilaku aktual wisatawan. NME dapat memberi pertimbangan dan mengarahkan perilaku kunjungan wisatawan yang sebenarnya, demikian juga fungsionalitas produk ekowisata dapat mempengaruhi perilaku aktual (kunjungan) wisatawan (Ramayah, Lee, and Mohamad, 2010). Literatur perilaku konsumen memperkuat teori ini dan terbukti menjadi penentu NME. Asumsi teori berkaitan dengan kontrol dilakukan dengan sengaja, manusia sangat rasional dalam menggunakan informasi secara teratur dan manusia melihat dampak setelah tindakannya benar-benar terlibat dalam lingkungan. PKE adalah puncak determinan dari NME (Mei, Ling, and Piew, 2012).

\section{TOURSN}

Mass Tourism - large numbers of people seeking replication of their own culture in institutionalised settings.

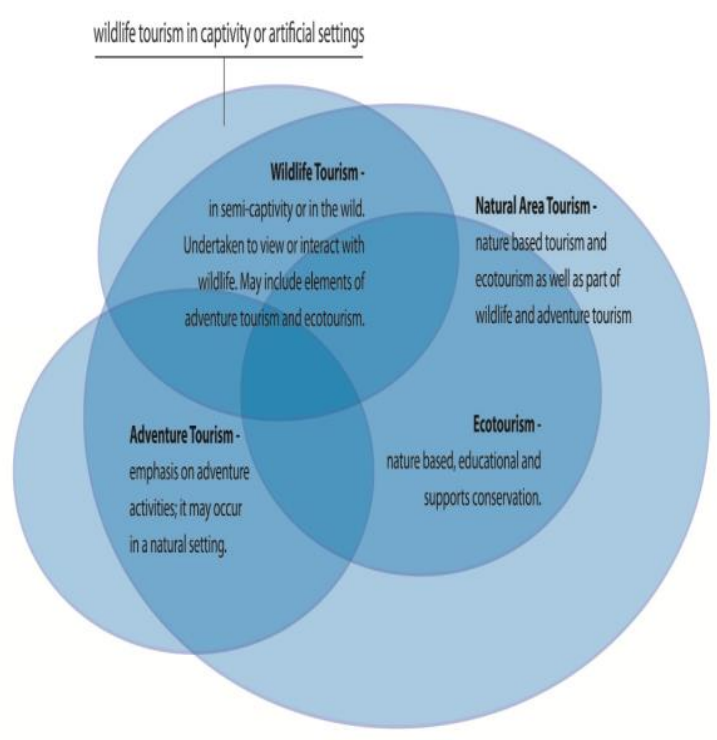

Alternative Tourism - forms of tourism generally characterised by small scale sustainable activities.

Gambar 2.2 Hubungan Ekowisata dengan Pariwisata Lainnya (Hill \& Gale, 2009)

\subsubsection{Persepsi Pengunjung Ekowisata \\ Persepsi pengunjung ekowisata}

(PPE) diperlukan untuk memprediksi dampak tindakan tertentu atau memberikan saran yang berguna untuk memperbaiki fasilitas yang ada 
atau menciptakan yang baru. Bila dipahami, pengalaman wisata bisa didesain untuk memenuhi kebutuhan wisatawan harus diperhitungkan saat membuat rencana pengelolaan untuk mencapai kesehatan ekologis kepuasan pengunjung dan kesejahteraan masyarakat lokal. Papageorgiou dan Vogiatzakis (2006) berpendapat bahwa manajemen ekowisata harus menekankan pada peningkatan pengetahuan jangka pendek dan perubahan perilaku pengunjung dalam jangka panjang. Keterpaduan konsep dan ketersediaan fasilitas harus dibangun untuk menawarkan pengalaman edukasi yang memuaskan pengunjung dan ini akan membantu wisatawan menghargai kawasan lindung.

PPE didefinisikan sebagai pengukuran keyakinan seseorang atas hasil tindakannya sendiri. Ini menyiratkan bahwa penilaian individu terhadap kriteria ekowisata mempengaruhi perilaku mereka terhadap ekowisata. Pengamatan terhadap PPE terkait kepercayaan pelanggan bahwa tindakannya akan berkontribusi terhadap masalah kerberlanjutan ekowisata (Vermeir \& Verbeke, 2006).

Kajian empiris ekowisata menunjukkan bahwa, PPE berpengaruh positif terhadap masalah ekowisata. Kepercayaan pelanggan memainkan peran penting dalam memerangi kerusakan ekowisata, wisatawan menjadi pendorong perilaku sadar secara ekologis (Sharma \& Sharma, 2013). Penelitian Kim and Han (2010); Paco and Rapose (2009) menunjukkan bahwa persepsi wisatawan dapat memprediksi niat konsumen untuk melakukan kunjungan ekowisata, dan pentingnya $K \boldsymbol{L}$ dalam memprediksi perilaku berorientasi lingkungan. Ini menunjukkan bahwa kepercayaan dan nilai dasar wisatawan memiliki dampak pada kesadaran perilaku eko-wisata. Dalam banyak kasus keyakinan hijau mempengaruhi perilaku kunjungan hijau. Oleh karena itu, dapat diduga bahwa wisatawan hijau menunjukkan PPE itu dapat mempengaruhi kemungkinan tujuan kunjungan ekowisata, PPE merupakan salah satu kekuatan pendorong perilaku proekowisata. PPE melibatkan keyakinan individu bahwa suatu peristiwa dapat terjadi atau dihentikan tergantung pada aktivitasnya.

\subsubsection{Kepedulian Lingkungan}

Wisatawan yang memiliki kepedulian terhadap lingkungan (KL) menunjukkan sikap positif, dan tingkat persepsi perilaku yang kuat, akan mendorong niat untuk membeli produk ekowisata (Albayrak, Aksoy and Caber, 2013). Kepedulian lingkungan sangat terkait dengan PKE. Jika seseorang peduli terhadap lingkungan, dia akan lebih memilih untuk membeli produk ekowisata (Rashid, 2009). Kepedulian terhadap lingkungan menunjukkan sejauh mana wisatawan menyadari masalah lingkungan dan mendukung upaya yang dilakukan untuk mengatasi masalah lingkungan dalam bentuk kesediaan wisatawan untuk berpartisipasi dalam upaya mencegah kerusakan lingkungan (Alibeli and Johnson, 2009).

Menurut Yazdanifard and Mercy (2011) dengan meningkatnya kesadaran wisatawan tentang masalah lingkungan, maka marketer harus dapat mengintegrasikan kesehatan lingkungan dan kesejahteraan wisatawan dan memastikan setiap fase perancangan produk hingga distribusi produk dilakukan dengan pendekatan ekowisata. Pelanggan suka membentuk asosiasi dengan merek yang ramah lingkungan.

Isu lingkungan telah menyertai perkembangan masyarakat global dan memberikan dampak yang berbeda pada manusia. Untuk waktu yang lama, perkembangan masyarakat mengandalkan konsumsi bahan bakar fosil dan sumber daya alam lainnya (Chang dan Cheng, 2011). Perhatian masyarakat terhadap isu lingkungan semakin meningkat. Banyak konsumen sadar bahwa perilaku pembelian mereka dapat membahayakan lingkungan, mulai mencari dan mengembangkan produk ramah lingkungan, bahkan terkadang membayar lebih untuk produk semacam itu (Kahn, 2007; Lee et al., 2010).

$K L$ dapat berubah menjadi perilaku yang menguntungkan secara ekologis dan menjadi salah keputusan pembelian ramah lingkungan (Paco and Rapose, 2009). Konsumen mencoba untuk menjalani gaya hidup yang lebih green, mencari hotel yang mengikuti praktik ramah lingkungan (Manaktola dan Jauhari, 2007).

Menurut Bohdanowicz (2006) bahwa peraktik perilaku konsumen berdampak serius terhadap lingkungan, industri pariwisata hanya tertarik pada perlindungan lingkungan asalkan mengurangi biaya operasi dan aktivitas, kesempatan untuk mengurangi dampak terhadap lingkungan dan meningkatkan keberlanjutan. Inilah alasan mengapa memilih industri perhotelan sebagai target penting dan berharap wisatawan bisa menjadi praktisi lingkungan. Demikian juga Liu et al. (2012), mengklaim bahwa preferensi konsumen dalam melakukan perilaku tertentu penting bagi lingkungan dan keputusan mengenai apakah membeli produk yang pro-lingkungan akan berdampak langsung pada perlindungan lingkungan. 
$K L$ secara individual adalah sikap umum dan determinasi tidak langsung terhadap perilaku spesifik. Artinya, $K \boldsymbol{K}$ seseorang akan berdampak pada perilaku tertentu melalui keyakinan dan sikap spesifik terhadap situasi. Oleh karena $K \boldsymbol{L}$ sebagai anteseden penting dalam menentukan PKE individual, dan memahami perilaku wisatawan untuk mengunjungi ekowisata dapat membantu pemerintah dan industri pariwisata dan perhotelan memahami pandangan wisatawan tentang green dan memberikan saran konstruktif untuk keberlanjutan ekowisata.

$K \boldsymbol{L}$ adalah sikap umum terhadap perlindungan lingkungan, merupakan faktor penentu dalam membuat orang mengubah perilaku mereka menjadi lebih ramah lingkungan. Semakin banyak masalah lingkungan yang terus berlanjut, para ilmuwan pariwisata mulai memperhatikan motivasi orang untuk menghasilkan perilaku spesifik yang terkait dengan lingkungan dan meyakinkan orang agar terlibat dalam perilaku pro-lingkungan. $\boldsymbol{K L}$ tidak mempengaruhi $P K E$ secara langsung, Bamberg's (2003) menemukan korelasi rata-rata antara $K \boldsymbol{L}$ dan perilaku. $K \boldsymbol{L}$ memiliki dampak langsung terhadap persepsi wisatawan ekowisata.

Pengaruh $\boldsymbol{K} \boldsymbol{L}$ terhadap ekowisata. $\boldsymbol{K} \boldsymbol{L}$ berkaitan dengan penilaian pengetahuan seseorang tentang seberapa baik dapat mencapai tujuan. Literatur menunjukkan bahwa $K L$ sebagai variabel potensial dalam mempengaruhi ekowisata (Gilg et al, 2010) artinya bahwa $K L$ berhubungan dengan NME.

Produk ekowisata berasal dari konsep perlindungan lingkungan dan mengunjunginya adalah perilaku perlindungan lingkungan yang spesifik. Studi sebelumnya menunjukkan bahwa bagi wisatawan yang peduli terhadap lingkungan mereka akan memiliki sikap yang baik terhadap produk atau layanan ramah lingkungan termasuk hotel yang akan dikunjungi (Aman et al., 2012; Han et al., 2009).

Studi yang dilakukan oleh Lee (2009) terhadap 6.010 anak muda di Hong Kong menyimpulkan bahwa (1) sikap yang berkaitan dengan masalah lingkungan, biasanya dianggap sebagai pertimbangan rasional terhadap pelestarian lingkungan. (2) $K L$ adalah prediktor NME dan PKE; (3) remaja perempuan menunjukkan nilai yang lebih tinggi daripada laki-laki terhadap kepedulian lingkungan serta keseriusan dalam memahami masalah ekologi, kewajiban terhadap lingkungan, niat dan perilaku terhadap produk ekowisata.
Ali et all, (2011) meneliti 400 responden dan hasilnya menunjukkan (1) bahwa NME memberikan pengaruh positif terhadap PKE yang sebenarnya (2) wisatawan yang memiliki niat positif terhadap produk ekowisata dan kesadaran terhadap isu lingkungan mempengaruhi preferensi wisatawan terhadap brand ekowisata.

Riset yang dilakukan oleh Hasan, et all, (2011) menunjukkan bahwa (1) wisatawan yang sadar lingkungan lebih memilih destinasi ekowisata dan lebih menyukai praktik ekowisata (2) NME merupakan variabel penting dalam memprediksi PKE, NME memiliki hubungan positif dengan perilaku, sikap dan motivasi kunjungan ekowisata (Sharma \& Sharma, 2014)

Hasil riset Flamm (2009) menyatakan bahwa (1) memahami keputusan pembelian pro-lingkungan sangat membantu perusahaan dalam meningkatkan kinerja lingkungan dan pembuatan kebijakan perusahaan. (2) perilaku pro-lingkungan dan kepemilikan kendaraan menyarankan agar pembuat kebijakan mengurangi kepemilikan dan penggunaan kendaraan rumah tangga. Kuminoff et all (2010) melakukan meta-analisis atas kemauan para wisatawan untuk membayar produk ekowisata dan menyarankan agar ada harga premium untuk produk ini.

\subsection{Penelitian Terdahulu}

\begin{tabular}{|c|c|c|c|c|c|}
\hline No & Peneliti & Tujuan & Hasil & $\begin{array}{l}\text { Kontr } \\
\text { ibusi }\end{array}$ & $\begin{array}{l}\text { Keterbat } \\
\text { asan }\end{array}$ \\
\hline 1 & $\begin{array}{l}\text { Lailatul } \\
\text { Qomariah, } \\
2009\end{array}$ & $\begin{array}{l}\text { Mengemba } \\
\text { ngkan } \\
\text { ekowisata } \\
\text { berbasis } \\
\text { masyarakat } \\
\text { di Taman } \\
\text { Nasional } \\
\text { Meru Betiri, } \\
\text { Jatim }\end{array}$ & $\begin{array}{l}\text { Persepsi } \\
\text { masyara } \\
\text { kat } \\
\text { terhadap } \\
\text { kawasan } \\
\text { TNMB } \\
\text { adalah } \\
\text { milik } \\
\text { negara } \\
\text { yang } \\
\text { dikelola } \\
\text { oleh } \\
\text { PHPA }\end{array}$ & $\begin{array}{l}\text { Progr } \\
\text { am } \\
\text { kegiat } \\
\text { an } \\
\text { ekowi } \\
\text { sata } \\
\text { berba } \\
\text { sis } \\
\text { masy } \\
\text { arakat }\end{array}$ & $\begin{array}{l}\text { Tidak } \\
\text { dapat } \\
\text { digenera } \\
\text { lisasi } \\
\text { Sample } \\
\text { Terlalu } \\
\text { Kecil }\end{array}$ \\
\hline 2 & $\begin{array}{l}\text { Yulianus, } \\
2016\end{array}$ & $\begin{array}{l}\text { Mengetahu } \\
\text { i pengaruh } \\
\text { kualitas } \\
\text { informasi } \\
\text { kawasan } \\
\text { ekowisata } \\
\text { hutan } \\
\text { Mbeliling } \\
\text { Kabupaten } \\
\text { Manggarai } \\
\text { Barat } \\
\text { terhadap } \\
\text { loyalitas } \\
\text { wisatawan }\end{array}$ & $\begin{array}{l}\text { Kualitas } \\
\text { informasi } \\
\text { manaje } \\
\text { men } \\
\text { yang } \\
\text { bagus } \\
\text { akan } \\
\text { berperau } \\
\mathrm{h} \text { positif } \\
\text { terhadap } \\
\text { loyalitas } \\
\text { wisataw } \\
\text { an } \\
\text { dalam } \\
\text { berkunju } \\
\text { ng di } \\
\text { hutan } \\
\text { Mbeliling }\end{array}$ & $\begin{array}{l}\text { Memb } \\
\text { erikan } \\
\text { hasil } \\
\text { positif } \\
\text { dalam } \\
\text { penge } \\
\text { mban } \\
\text { gan } \\
\text { ekowi } \\
\text { sata } \\
\text { di } \\
\text { hutan } \\
\text { Mbelili } \\
\text { ng, } \\
\text { Mang } \\
\text { garai }\end{array}$ & $\begin{array}{l}\text { Sample } \\
\text { terlalu } \\
\text { sedikit } \\
\text { karena } \\
\text { obyek } \\
\text { wisata } \\
\text { belum } \\
\text { banyak } \\
\text { dikenal } \\
\text { masyara } \\
\text { kat luas }\end{array}$ \\
\hline
\end{tabular}

\subsection{Implementasi Sistem, Hasil Dan Pembahasan}

Hasil penelitian menunjukkan bahwa nilai besar ditempatkan pada persepsi pengunjung untuk meningkatkan jumlah pengunjung yang datang ke wilayah Bantul. Dalam mengevaluasi hasil ini, penting untuk 
melatih penduduk lokal dan faktor pendukung lainnya seperti fasilitas pariwisata untuk membantu wisatawan dalam menikmati keindahan alam dan menikmati waktu yang menyenangkan. Ketika wisatawan pulang akan membawa memori yang bisa diceritakan melalui berbagai media. Kondisi ini akan berpengaruh terhadap meningkatnya persepsi wisatawan dengan hal yang positif sehingga akan meningkatkan pertumbuhan ekonomi dan pariwisata di Kabupaten Bantul itu sendiri khususnya obyek wisata Mangrove. Beberapa hal yang perlu dilakukan yaitu dengan pendampingan pengembangan bagi masyarakat sekitar obyek Ekowisata Hutan Mangrove Baros Bantul. Program pendampingan bagi masyarakat sekitar obyek Ekowisata Hutan Mangrove Baros Bantul merupakan proses pencapaian kemandirian pengelolaan sehingga program pendampingan ini akan diberhentikan ketika masyarakat sekitar dirasa sudah siap untuk melanjutkan program secara mandiri.

\section{Perilaku Kunjungan Wisatawan \\ Ekowisata}

Hasil dilapangan menunjukan bahwa wisatawan datang ke Ekowisata Hutan Mangrove Baros, Bantul adalah dengan mencari tahu dan melakukan eksplorasi terhadap kondisi wisata Baros ini. Wisatawan melakukan edukasi dan membagikan hasil eksplorasi kedalam media sosial dan bercerita kepada orang lain akan keindahan Baros. Perilaku yang wisatawan juga menunjukan keinginan untuk belajar budaya dan adat istiadat setempat, serta bagaimana berperilaku mencintai alam berupa flora dan fauna yang terdapat dalam Ekowisata Hutan Mangrove Baros Bantul

\section{Minat Wisatawan}

Hasil pengamatan dilapangan menunjukan bahwa minat wisatawan untuk berkunjung ke obyek Ekowisata Hutan Mangrove Baros, Bantul adalah untuk menikmati keindahan alam terbuka berupa hutan mangrove. Selain itu minat para wisatwan melakukan kunjungan ke obyek Ekowisata Hutan Mangrove Baros, Bantul memiliki alasan untuk wisata educatif, santai, petualangan dan berekreasi. Minat wisatawan untuk mengunjungi obyek Ekowisata Hutan Mangrove Baros, Bantul adalah sebagai berikut ini

\begin{tabular}{|l|l|}
\hline Minat Wisatawan & Jumlah (\%) \\
\hline Melihat Hutan Mangrove & $52 \%$ \\
\hline Keindahan Alam & $30 \%$ \\
\hline Wisata Educative & $18 \%$ \\
\hline
\end{tabular}

\section{Kepedulian Lingkungan}

Kepedulian terhadap lingkungan sangat diperhatikan oleh perilaku wisatawan di Baros ini. Para wisatawan menikmati keindahan alam tanpa melakukan perusakan lingkungan, selain itu di Baros ini juga terdapat paket wisata educative tentang wisata menanam bakau. Disini para wisatawan melakukan eksplorasi dan memahami betapa pentingnya cinta alam dan imbas dari kepedulian lingkungan tehadap habitat yang ada disekitar Mangrove Baros.

\section{Analisis SWOT}

Berdasarkan hasil dilapangan dapat dilihat berdasarkan kekuatan, kelemahan, peluang dan ancaman yang terkait dengan kondisi di lapangan terhadap faktor internal dan eksternal tehadap minat wisatawan antara lain sebagai berikut :

a. Perlunya mengembangkan program kegiatan pengembangan yang menggabungkan potensi alam dan budaya untuk ;lebih menarik minat kunjungan wisatawan.

b. Mengenalkan dan mempromosikan potensi wisata Mangrove Baros

c. Pengembangan sarana dan prasarana

d. Peningkatan kemampuan SDM masyarakat lokal dalam pelatihan manajerial dan pelatihan teknis penyambutan wisatwan

e. Pebaikan akses menuju ke Wisata Mangrove Baros Bantul

\subsection{Kesimpulan}

Perilaku wisatawan terhadap mminat kunjungan ke Hutan Mangrove Baros sangat besar, namun masih perlu diimbangi dengan strategi pengambangan obyek wisata ini, mengingat jenis minat wisata pada ekowisata masih terbatas namun berimbas besar terhadap kenajuan suatu daerah. Penelitian selanjutnya dapat mengembangakan dengan citra khusus wisata minat khusus ekowisata terutama Mangrove yang sudah jelas segmen pasar dan motivasi perilaku wisatawan yang datang dan berkunjung.

\section{Daftar Pustaka}

[1] Albayrak, T., Aksoy, S., and Caber, M. 2013. The effect of environmental concern and scepticism on green visit behaviour. Marketing Intelligence and Planning, Vol 31 No 1, pp 27 - 39.

[2] Ali, A., Khan, A. A., Ahmed, I., and Shahzad, W. 2011. Determinants of Pakistani Consumers' Green Visit Behavior: Some Insights. International Journal of Business and Social Science, Vol 2 No 3, pp 217-226. 
[3] Alibeli, M., and Johnson, C. 2009. Environmental Concern: A Cross National Analysis. Journal of International and cross-cultural studies, Vol 3 No 1, 1-10.

[4] Aman, L., Harun, A., and Hussein, Z. 2012. The Influence of Environmental Knowledge and Concern on Green Visit Intention the Role of Attitude as a Mediating Variable. British Journal of Arts and Social Sciences, Vol 7 No 2, pp145167.

[5] Arnau, R. C., and Thompson, B. 2000. Second order confirmatory factor analysis of the WAIS- III. Assessment. Vol 7 No 3, pp 237-246.

[6] Anderson, J. C. and Gerbing, D. W. 1988. Structural equation modeling in practice: a review and recommended two-step approach. Psychological Bulletin. Vol 103 No 3, pp 411-423.

[7] Bamberg, S., 2003. How does environmental concern influence specific environmentally related behaviors? A new answer to an old question. Journal of Environmental Psychology. Vol 23 No1, pp 21-32.

[8] Bandalos, D. L. 2002. The effects of item parceling on goodness-of-fit and parameter estimate bias in structural equation modeling. Structural Equation Modeling. Vol 9 No 1, pp 78-102

[9] Becker, J. M., Rai, A., Ringle, C. M., and Völckner, F. 2013. Discovering unobserved heterogeneity in structural equation models to avert validity threats. Mis Quarterly. Vol 37 No 3, pp 665-694.

[10]Budeanu, A., 2007. Sustainable tourist behaviour - a discussion of opportunities for change. International Journal of Consumer Studies Vol 31 No 5, pp 499508.

[11] Chang, J.E., Cheng, L., 2011. Evolution and prospect of environmental technology. Science Development Vol 45 No 7, 103108.

[12] Chen YS, Lai SB, Wen CT. 2006. The influence of green innovation performance on corporate advantage in Taiwan. Journal of Business Ethics. Vol 67 No 4, pp 331339.

[13] Chin, C., Moore, S. and Wallington, T. 2000. National Eco-tourism: Visitors' Perspectives on Environmental Impacts and their Management. Journal Sustainability Tourism. Vol 8 No 1, pp 2035.

[14] Farrell, T. and Marion, J. 2001. Identifying and assessing ecotourism visitor impacts at eight protected areas in Costa Rica and
Belize. Environmental Conservation. Vol 28 No 3, pp 215-225.

[15] Flamm, B., 2009. The impacts of environmental knowledge and attitudes on vehicle ownership and use. Transportation Research Part D: Transport and Environment Vol 14 No 4, pp 272-279.

[16] Gilg A, Barr S, Ford N. 2005. Green consumption or sustainable lifestyles? Identifying the sustainable consumer. Futures. Vol 37 No 6 pp 481-504.

[17] Hair, J. F., Black, W.C., Babin, B. J., Anderson, R. E., and Tatham, R. L. 2005. Multivariate data analysis $6^{\text {th }}$. Upper Saddle River, New Jersey: Pearson Prentice Hall.

[18] Hair, J. F., Sarstedt, M., Hopkins, L., and Kuppelwieser, G.V. 2014. Partial least squares structural equation modeling: An emerging tool in business research. European Business Review. Vol 26 No 2, pp 106-121.

[19]Han, H., Hsu, L.-T., Lee, J.S., 2009. Empirical investigation of the roles of attitudes towards green behaviors, overall image, gender, and age in hotel customers' eco-friendly decision-making process. International Journal of Hospitality Management. Vol 28, pp 519528.

[20] Hasan, A., Subhani, Imtiaz, M., Osman, and Amber. 2011. The crux of green marketing: an empirical effusive study. European Journal of Social Science, Vol 27 No 3, 425-435.

[21] Hox, J.J and Bechger, T.M. 1998, An Introduction to Structural Equation Modeling. Family Science Review. Vol 11, pp 354-373.

[22] Hu, L., and Bentler, P. M. 1999. Cutoff criteria for fit indexes in covariance structure analysis: conventional criteria versus new alternative. Structural Equation Modeling. Vol 6 No 1, pp 1-55.

[23] Kahn, M.E., 2007. Do greens drive hummers or hybrids? Environmental ideology as a determinant of consumer choice. Journal of Environmental Economics and Management. Vol 54 No 2, pp 129-145.

[24] Kim Y, Choi SM. 2005. Antecedents of green purchase behavior: An examination of collectivism, eco-tourism concern, and perception consumer. Advances in Consumer Research. Vol 32, pp 592 607.

[25] Kim, Y., Han, H., 2010. Intention to pay conventional-hotel prices at a green hotela modification of the theory of planned 
behavior. Journal of Sustainable Tourism Vol 18 No 8, pp 997-1014.

[26] Klein, A. and Moosbrugger, H. 2000. Maximum likelihood estimation of latent interaction effects with the LMS method. Psychometrica. Vol 65 No 4, pp 457-474.

[27] Kuminoff, N.V., Zhang, C., Rudi, J., 2010. Are travelers willing to pay a premium to stay at a "green" hotel? Evidence from an internal meta-analysis of hedonic price premia. Agricultural and Resource Economics Review Vol 39 No 3, pp 468484.

[28] Lafuente R. 2010. Defining and measuring eco-tourism consciousness. International Journal of the Sociological Science. Vol 68 No 3, pp 731-755.

[29] Lee, J.-S., Hsu, Jane, L.-T., Han, H., Kim, Y., 2010. Understanding how consumers view green: how a green image can influence behavioural intentions. Journal of Sustainable Tourism Vol 18 No 7, pp 901914.

[30] Lee, K. 2009. Gender differences in Hong Kong adolescent consumers' green intention behavior. Journal of Consumer Marketing, Vol 26 No 2, pp 87-96.

[31] Liu, X., Wang, C., Shishime, T., Fujitsuka, T., 2012. Sustainable consumption: green purchasing behaviours of urban residents in China. Sustainable Development. Vol 20 No 4, pp 293-308.

[32] Manaktola, K., Jauhari, V., 2007. Exploring consumer attitude and behaviour towards green practices in the hotel accommodation industry in India. International Journal of Contemporary Hospitality Management Vol 19 No 5, pp 364-377.

[33] Marion, J.L. and Leung, Y. 2001. Trail resource impacts and an examination of alternative assessment techniques. Journal of park and Recreation Administration, Vol 19 No 3, pp 17-37.

[34]Mei, O. J., Ling, K. C., and Piew, T. H. 2012. The Antecedents of Green Visit Intention among Malaysian Consumers. Asian Social Science, Vol 8 No 13, pp 248-263.

[35]Noar, S. M. 2003. The role of structural equation modeling in scale development. Structural Equation Modeling. Vol 10 No 4, pp 622-647.

[36]Paco, A., Rapose, M., 2009. "Green" segmentation: an application to the Portuguese consumer market. Marketing Intelligence and Planning Vol 27 No 3, pp 364-379.

[37] Papageorgiou, K. and Vogiatzakis, I. 2006. Nature protection in Greece: an appraisal of the factors shaping integrative conservation and policy effectiveness. Environment Science. Policy, Vol 9 No 5, pp 476-486.

[38]Rahbar, E., and Wahid, N. A. 2011. Investigation of green marketing tools' effect on consumers' visit behavior. Business Strategy Series, Vol 12 No 2, 73 - 83.

[39] Ramayah, Lee, J. W., and Mohamad, O. 2010. Green product visit intention: Some insights from a developing country. Resources, Conservation and Recycling, Vol 54 No 12, pp 1419-1427.

[40] Rashid, N. R. 2009. Awareness of Ecolabel in Malaysia's Green Marketing Initiative. International Journal of Business and Management, Vol 4 No 8, pp 132-141.

[41] Schermelleh-Engel, K., Moosbrugger, H., and Müller, H. 2003. Evaluating the fit of structural equation models: Tests of significance and descriptive goodness-offit measures. Methods of Psychological Research Online. Vol 8 No 2, pp 23-74.

[42] Sharma N, Sharma CS. 2014. Studying green purchasing intentions through ecotourism motivation. Proceeding of Contemporary Management Practices Opportunities and Challenges. 323-328.

[43] Sharma N, Sharma CS. 2013. Encouraging green purchasing behavior through green branding. Business Analyst. Vol 34 No 2 pp 65-76.

[44] Sihar Tambun, 2014. Metode SEM dan Interpretasi Hasil Penelitian Dengan Menggunakan AMOS. Pelatihan SEM dengan AMOS. http://dosen.uta45jakarta.ac.id. Akses 15 April 2017

[45] Spanou, S. Tsegenidi, K. and Georgiadis, T. 2012. Perception of Visitors' Environmental Impacts of Ecotourism, Intrternational Journal Environment Responsibility., Vol 6 No 1, pp 245-258.

[46] Soemarno, 2011. Metode Penelitian : Structural Equation Modelling http://marno. lecture.ub.ac.id. Akses 15 April 2017

[47] Vermeir I, Verbeke W. 2006. Sustainable food consumption: Exploring the consumer attitude-behavioral intention gap. Journal of Agricultural and Environmental Ethics. Vol 19 No 2, pp 169-94.

[48] Yazdanifard, R., and Mercy, I. E. 2011. The impact of Green Marketing on Customer satisfaction and Environmental safety. International Computer Communication and Management, Vol 5, pp 637-64 